\title{
PTEN loss of expression predicts cetuximab efficacy in metastatic colorectal cancer patients
}

\author{
M Frattini", 1,3, P Saletti ${ }^{2,3}$, E Romagnani ${ }^{2,4}$, V Martin', F Molinari', M Ghisletta', A Camponovo', LL Etienne', \\ F Cavalli ${ }^{2}$ and L Mazzucchelli'
}

'Institute of Pathology, via in Selva 24, CH-6600 Locarno, Switzerland; ${ }^{2}$ Oncology Institute of Southern Switzerland, Ospedale San Giovanni, CH-6500 Bellinzona, Switzerland

\begin{abstract}
To evaluate whether the epidermal growth factor receptor (EGFR), K-Ras and PTEN, all members of the EGFR signalling pathway, may affect the clinical response in cetuximab-treated metastatic colorectal cancer ( $m C R C$ ) patients. Twenty-seven cetuximab-treated $\mathrm{mCRC}$ patients were evaluated for drug response and investigated for EGFR protein expression and gene status, K-Ras mutational status and PTEN protein expression. Ten patients achieved a partial response (PR) to cetuximab-based therapy. All 27 patients showed EGFR protein overexpression. Epidermal growth factor receptor gene amplification was observed in eight out of 27 (30\%) and chromosome 7 marked polysomy in 16 (59\%) patients. Partial response was observed in six out of eight patients with EGFR gene amplification, four out of 16 with marked polysomy and none out of three with eusomy $(P<0.05)$. The K-Ras wild-type sequence was observed in 17 patients, and nine of them experienced a PR. Conversely, K-Ras was mutated in 10 cases, of which one patient experienced a PR $(P<0.05)$. The PTEN protein was normally expressed in 16 patients, and 10 of them achieved a PR. In contrast, no benefit was documented in I I patients with loss of PTEN activity $(P<0.00$ I). Patients with EGFR gene amplification or chromosome 7 marked polysomy respond to cetuximab. In addition to K-Ras mutations, we demonstrate for the first time that the loss of PTEN protein expression is associated with nonresponsiveness to cetuximab.
\end{abstract}

British Journal of Cancer (2007) 97, | |39- | |45. doi: I0.1038/sj.bjc.6604009 www.bjcancer.com

Published online 16 October 2007

(C) 2007 Cancer Research UK

Keywords: colorectal cancer; cetuximab; EGFR; K-Ras; PTEN; fluorescent in situ hybridisation

Metastatic colorectal cancer ( $\mathrm{mCRC}$ ) is a leading cause of cancer death worldwide, and despite recent advances in chemotherapeutic treatment, there is a continuous need for more effective therapies. More recently, specific molecular processes have been targeted for therapeutic interventions. The epidermal growth factor receptor (EGFR) is one of four HER-family tyrosine kinases (EGFR, erbB2, erbB3, erbB4) that initiates intracellular proliferation signalling. The activation results in proliferation and survival through the Ras/Raf/MEK/ERK or PI3K/PTEN/AKT pathways, respectively (Baselga, 2001). The activated EGFR also regulates the production of angiogenic factors and permits tumour invasion through extracellular matrix components. In mCRC, the expression of EGFR, which can be demonstrated in approximately $70 \%$ of cases, correlates with poor prognosis (Mayer et al, 1993). Given the myriad of downstream effects, its frequency of overexpression, and its correlation with prognosis, various approaches have been considered to inhibit EGFR, including monoclonal antibodies $(\mathrm{MoAb})$ and small molecule inhibitors. In mCRC, the clinical development focused on cetuximab, a chimaeric mouse/human $\mathrm{MoAb}$ of the IgG1 subclass, that binds to the extracellular region of the receptor and functions as a competitive antagonist that inhibits

\footnotetext{
*Correspondence: Dr M Frattini; E-mail: milo.frattini@ti.ch

${ }^{3}$ These authors contributed equally to this work as first authors

${ }^{4}$ Current address: Nuovo Ospedale di Sassuolo (MO), Italy.

Received 19 July 2007; accepted I September 2007; published online 16 October 2007
}

ligand binding, leading to the blockage of EGFR downstream pathway.

Several clinical trials including cetuximab have been conducted in mCRC, not only in patients refractory to irinotecan-based chemotherapy, but also as single agent or as first- or second line in combination with oxaliplatin-based regimens. All these studies indicated that only a subgroup of patients treated with cetuximab may benefit from the drug (Rosenberg et al, 2002; Van Laethem et al, 2003; Cunningham et al, 2004; Saltz et al, 2001, 2004; Tabernero et al, 2004; Jennis et al, 2005; Borner et al, 2006; Folprecht et al, 2006; Venook et al, 2006; Wilke et al, 2006). Based on preclinical findings, it should be outlined that the trials including cetuximab have been performed in patients who expressed EGFR protein in primary tumours based on immunohistochemistry (IHC). However, no correlation has been shown between efficacy of cetuximab and intensity of EGFR staining in tumours (Cunningham et al, 2004; Saltz et al, 2004). In addition, response to cetuximab has been observed also in patients with EGFR-negative tumours (Chung et al, 2005). These data indicate that EGFR expression by IHC is insufficient to determine candidacy for cetuximab therapy. No reliable markers have so far been characterised to identify patients who will benefit from cetuximab therapy, and only skin reaction has been significantly associated with response and overall survival (OS) (Cunningham et al, 2004; Saltz et al, 2004). However, recent data suggest that the EGFR gene status may predict response to cetuximab (Moroni et al, 2005), while $K$-Ras point mutations seem to confer resistance 
to this drug (Lievre et al, 2005; Di Fiore et al, 2007). Our study aimed to examine whether molecular determinants such as the EGFR gene status and the EGFR downstream cascade members $K$ Ras and PTEN, which are altered in a significant proportion of sporadic CRC independently of the EGFR status, may serve as markers in predicting response in patients with mCRC treated with cetuximab.

\section{PATIENTS AND METHODS}

\section{Patient population and treatment regimens}

We analysed 27 consecutive patients, who gave informed consent, with histologically confirmed mCRC at the Institute of Pathology, Locarno, Switzerland. All patients were treated with cetuximabbased regimens at the Oncology Institute of Southern Switzerland, 18 of them treated within clinical trials. All patients had EGFR expression in their primary tumour specimens at IHC.

With the exception of four patients who received cetuximab as frontline therapy, the others had failed at least one prior chemotherapy regimen (Table 1). For those who progressed on irinotecan-based chemotherapy, the MoAb was administered in combination with irinotecan given at the same dose and schedule previously used. Cetuximab was administered at standard loading dose of $400 \mathrm{mg} \mathrm{m}^{-2}$ over $2 \mathrm{~h}$, followed by weekly $250 \mathrm{mg} \mathrm{m}^{-2}$ over $1 \mathrm{~h}$. Treatment was continued until progressive disease (PD) or toxicity occurred, according to the standard criteria (Therasse et al, 2000) or the specific trial guidelines.

\section{Clinical evaluation and response criteria}

The response was assessed every 6 weeks with radiological examination (computerised tomodensitometry or magnetic reso-

Table I Patient's characteristics and response by treatment
Solid Tumors) criteria were adopted for evaluation, and classified into partial response (PR), stable disease (SD) and PD. Patients with SD or PD were defined as nonresponders (Therasse et al, 2000). Response to therapy was also evaluated retrospectively by independent radiologists.

\section{Molecular analyses}

Primary tumour specimens were fixed in $10 \%$ buffered formalin and embedded in paraffin, and data processing was accomplished at the Institute of Pathology, Locarno, Switzerland. All formalinfixed paraffin-embedded tumour blocks were reviewed for quality and tumour content, and a single representative tumour block from each case, containing at least $70 \%$ of neoplastic cells, was selected for immunohistochemical, cytogenetic and molecular analyses. Genomic DNA was extracted using the QIAamp Mini kit (Qiagen, Chatsworth, CA, USA) according to the manufacturer's instructions.

Epidermal growth factor receptor: IHC Epidermal growth factor receptor protein expression was evaluated using the EGFR PharmDX kit (Dako Cytomation, Glostrup, Denmark) on 3- $\mu \mathrm{m}$ thick tissue sections without knowledge of clinical data or the results of other analyses. The intensity of reaction was classified as score $1+, 2+$ or $3+$, on the basis of the percentage of positive cells and the intensity of staining, according to the manufacturer's instructions ( $<5 \%, 5-50 \%$ and $>50 \%$ of cells, respectively). As controls, we used those included in the kit.

Microsatellite instability The status of microsatellite instability (MSI) was assessed by the analysis of the microsatellite loci included in the panel of Bethesda (BAT25, BAT26, D2S123, D5S346, D17S250), as reported previously (Frattini et al, 2004). Microsatellite instability was confirmed by the presence of an additional peak in tumour sample in comparison with normal paired tissue.

\begin{tabular}{|c|c|c|c|c|c|c|c|}
\hline Patients & Sex & $\begin{array}{c}\text { Age } \\
\text { (years) }\end{array}$ & Previous therapies & Cetuximab line & Regimen & Best response & $\begin{array}{l}\text { Duration of } \\
\text { response (weeks) }\end{array}$ \\
\hline I & $\mathrm{F}$ & 65 & FOLFOX & 2nd & CPTII-b/r+cetuximab (CT) & PR & 8 \\
\hline 2 & M & 67 & FOLFOX; CPTII & $3 r d$ & CPTII-b/r+cetuximab & PD & NA \\
\hline 3 & M & 60 & FOLFOX; CAP; FOLFIRI & 4th & CPTII-b/r+cetuximab (CT) & PD & NA \\
\hline 4 & M & 82 & CAPOX & 2nd & CPTI I-b/r+cetuximab (CT) & PD & NA \\
\hline 5 & M & 78 & CAP; FOLFOX; FOLFIRI & 4th & CPTI।-b/r+cetuximab (CT) & PD & NA \\
\hline 6 & $\mathrm{~F}$ & 63 & CPTII & 2nd & CPTI।-b/r+cetuximab (CT) & PD & NA \\
\hline 7 & M & 72 & CPT। I & $2 n d$ & CPTI I-b/r+cetuximab (CT) & PD & NA \\
\hline 8 & $\mathrm{~F}$ & 59 & FOLFIRI & 2nd & CPTII-b/r+cetuximab (CT) & PR & 48 \\
\hline 9 & M & 69 & FOLFIRI & $2 n d$ & CPTI I-b/r+cetuximab (CT) & PR & 16 \\
\hline 10 & M & 59 & FOLFOX; FOLFIRI & $3 r d$ & CPTII-b/r+cetuximab & PR & 48 \\
\hline । & M & 67 & FOLFOX; CPTII & $3 r d$ & CPTI I-b/r+cetuximab (CT) & PD & NA \\
\hline 12 & M & 69 & FOLFOX & 2nd & CPTI I-b/r+cetuximab (CT) & PD & NA \\
\hline 13 & M & 79 & CAPOX; CPTII & $3 r d$ & CPTI।-b/r+cetuximab & PR & 13 \\
\hline 14 & M & 65 & None & Ist & CAPOX+cetuximab (CT) & PD & NA \\
\hline 15 & $\mathrm{~F}$ & 75 & CAPOX; FOLFIRI & $3 r d$ & CPTII-b/r+cetuximab & PD & NA \\
\hline 16 & M & 64 & 5FU; CAPOX; FOLFIRI & 4th & CPTII-b/r+cetuximab (CT) & PR & 12 \\
\hline 17 & M & 72 & FOLFOX; CAPIRI & 3rd & CPTII-b/r+cetuximab (CT) & PR & 28 \\
\hline 18 & $\mathrm{~F}$ & 72 & 5FU/LV; CPTII & $3 r d$ & CPTI I-b/r+cetuximab (CT) & SD & 8 \\
\hline 19 & M & 66 & CAPIRI; CPTII & $3 r d$ & CPTII-b/r+cetuximab & PD & NA \\
\hline 20 & $\mathrm{~F}$ & 63 & None & Ist & CAPOX+cetuximab (CT) & PR & 8 \\
\hline 21 & $\mathrm{~F}$ & 84 & CAP; CPTII & $3 r d$ & CPTI।-b/r+cetuximab & PD & NA \\
\hline 22 & M & 59 & CAPOX/BV; FOLFIRI & $3 r d$ & CPTII-b/r+cetuximab & SD & I \\
\hline 23 & M & 78 & FOLFOX; CPTII & $3 r d$ & CPTII-b/r+cetuximab & PD & NA \\
\hline 24 & $\mathrm{~F}$ & 29 & FOLFOX; FOLFIRI & $3 r d$ & CPTI।-b/r+cetuximab (CT) & SD & 16 \\
\hline 25 & M & 58 & FOLFOX; CPTII & $3 r d$ & CPTII-b/r+cetuximab & PR & 16 \\
\hline 26 & M & 70 & None & lst & CAPOX+cetuximab (CT) & PR & 13 \\
\hline 27 & $\mathrm{~F}$ & 44 & None & Ist & CAPOX+cetuximab (CT) & PD & NA \\
\hline
\end{tabular}

Abbreviations: BV, bevacizumab; CAP, capecitabine; CAPIRI, irinotecan and CAP; CAPOX, oxaliplatin and CAP; CPTI I-b/r, irinotecan-based regimen; CT, clinical trial; F, female; 5FU, fluorouracil; FOLFIRI, irinotecan, 5FU and folinic acid; M, male; FOLFOX, oxaliplatin, 5FU and folinic acid; NA, not applicable; PD, progressive disease; PR, partial response; $\mathrm{SD}$, stable disease. 
Epidermal growth factor receptor: fluorescent in situ hybridization Epidermal growth factor receptor gene status evaluation was performed by fluorescent in situ hybridization (FISH) on $3-\mu \mathrm{m}$ thick tissue sections. Tissue sections were treated using Paraffin Pretreatment kit II (Vysis, Downer's Grove, IL, USA) according to the manufacturer's instructions. Dual-colour FISH assay was performed using LSI EGFR/CEP7 probes (Vysis). The LSI EGFR probe is labelled in SpectrumOrange and covers an approximately $300 \mathrm{~kb}$ region that contains the entire EGFR gene at $7 \mathrm{p} 12$. The CEP7 probe, labelled in SpectrumGreen, hybridises to the alpha satellite DNA located at the centromere of chromosome 7 (7p11.1 q11.1). Target sections and probe were co-denatured at $75^{\circ} \mathrm{C}$ for $5 \mathrm{~min}$ and allowed to hybridise overnight at $37^{\circ} \mathrm{C}$. Post-hybridisation stringency wash was carried out in water bath at $72^{\circ} \mathrm{C}$ for $5 \mathrm{~min}$. After washing twice and drying at room temperature for $10 \mathrm{~min}$, slides were mounted with $4^{\prime} 6$-diamidino-2-phenylindole (DAPI II; Vysis). Fluorescent in situ hybridization signals were evaluated with a Zeiss Axioscope equipped with single and triple band pass filters. Image for documentation were captured using AxioCam camera and processed using the AxioVision system. Patients showing two chromosome 7 in the vast majority of cells were classified as eusomic. Patients with an aberrant number of chromosome 7 , defined as more than 4 in at least $50 \%$ of cells, were classified as markedly polysomic. Patients with a ratio more than 3 between EGFR gene and chromosome 7 centromere signals in at least $10 \%$ of cells were classified as having EGFR gene amplification.

K-Ras mutational status: sequencing We searched for K-Ras point mutations in codons 12 and 13, two hotspots that include more than $95 \%$ of mutations in this gene, as already reported (Frattini et al, 2004). All samples were subjected to automated sequencing by ABI PRISM 3100 (Applied Biosystems, Foster City, CA, USA) and analysed with Chromas software. Each sequence reaction was performed at least twice, starting from independent PCR reactions. In each case, the detected mutation was confirmed in the sequence as sense and antisense strands.

PTEN expression: IHC PTEN protein expression status by IHC on $3-\mu \mathrm{m}$ tissue sections was performed and evaluated according to the literature (Frattini et al, 2005; Saal et al, 2005). The Anti-PTEN Ab-2 (Neomarkers, Fremont, CA, USA) was applied at $1: 50$ dilution. PTEN protein expression was detected mainly at cytoplasmic level, although occasional nuclear positivity was present. We considered PTEN negative tumours those showing a dramatical reduction or absence of immunostaining in at least $50 \%$ of cells, as compared with the internal control. The evaluations were performed without knowledge of clinical data or the results of other analyses.

\section{Statistical considerations}

The objective tumour response was the end point of our exploratory study. The two-tailed Fisher's exact test was used to calculate $P$-value for association between the gene alterations and response to cetuximab. The level of significance was set at $P=0.05$.

The OS time was calculated as the period from the first day of cetuximab treatment until death from any cause, or the date of the last follow-up.

\section{RESULTS}

A total of 27 patients were analysed, including nine women and 18 men, with a median age of 67 years (range, 29-84 years). Colon and rectal cancers were diagnosed in 19 and eight patients, respectively, and synchronous metastases were found in 19 patients $(70 \%)$. Cetuximab was administered in combination with chemotherapy as upfront therapy in four cases, as second line in seven cases, as third line in 13 patients and as fourth line in three cases. Ten patients (37\%) achieved PR after cetuximab-based therapy, and the median duration of response was 21 months (range, 8-48 months). Characteristics and response by treatment are summarised in Table 1.

\section{Microsatellite instability}

Using the Bethesda panel, none of tumours showed MSI (data not shown).

\section{Epidermal growth factor receptor: IHC and FISH}

Table 2 summarises the immunohistochemical, cytogenetic and molecular features. All patients had EGFR-positive tumours at IHC, five cases (19\%) were classified as score $1+$, nine cases $(33 \%)$ as score $2+$ and $13(48 \%)$ as score $3+$. By FISH, three (11\%) patients showed eusomy, 16 (59\%) patients were highly polysomic on chromosome 7 and eight (30\%) patients showed EGFR amplification (Figure 1). Five patients (Table 2) presented rare cells with $E G F R$ amplification associated with a large majority $(>50 \%)$ of cells with marked polysomy, and consequently they were classified as highly polysomic. We did not find any significant correlation by comparing the EGFR protein expression (by IHC) and its gene status (by FISH). In fact, those with eusomy showed either score $1+(66 \%)$ or score $3+$ staining (33\%). Polysomy correlated with score $1+$ in $6 \%$, score $2+$ in $44 \%$ and score $3+$ in $50 \%$. Patients who had gene amplification were equally distributed, with prevalence in favour of score $3+$ (score $1+$, $2+$ and $3+: 25,25$ and $50 \%$, respectively).

Table 2 Immunohistochemical, cytogenetic and molecular data

\begin{tabular}{|c|c|c|c|c|}
\hline Patients & EGFR: IHC & EGFR: FISH & K-Ras: status & PTEN: IHC \\
\hline 1 & $1+$ & A & WT & Pos \\
\hline 2 & $2+$ & A & $13 \mathrm{GaC}$ & $\mathrm{Neg}$ \\
\hline 3 & $3+$ & $P$ & $12 \mathrm{GcT}$ & Pos \\
\hline 4 & $1+$ & P & WT & $\mathrm{Neg}$ \\
\hline 5 & $3+$ & $P$ & $12 \mathrm{GcT}$ & Pos \\
\hline 6 & $2+$ & $\mathrm{P}$ & 12GaT & $\mathrm{Neg}$ \\
\hline 7 & $2+$ & $P$ & WT & $\mathrm{Neg}$ \\
\hline 8 & $3+$ & A & WT & Pos \\
\hline 9 & $3+$ & A & WT & Pos \\
\hline 10 & $2+$ & P* & WT & Pos \\
\hline 11 & $1+$ & E & $13 \mathrm{GaC}$ & $\mathrm{Neg}$ \\
\hline 12 & $3+$ & E & I2GaT & Pos \\
\hline 13 & $3+$ & A & WT & Pos \\
\hline 14 & $3+$ & $\mathrm{p} *$ & WT & Neg \\
\hline 15 & $2+$ & $A$ & $12 \mathrm{tGT}$ & $\mathrm{Neg}$ \\
\hline 16 & $2+$ & $P$ & WT & Pos \\
\hline 17 & $1+$ & A & WT & Pos \\
\hline 18 & $2+$ & P* & $12 \mathrm{GaT}$ & Pos \\
\hline 19 & $3+$ & $\mathrm{P} *$ & WT & $\mathrm{Neg}$ \\
\hline 20 & $3+$ & $P$ & $13 \mathrm{GaC}$ & Pos \\
\hline 21 & $3+$ & P & $12 \mathrm{GaT}$ & Pos \\
\hline 22 & $1+$ & $\mathrm{E}$ & WT & Pos \\
\hline 23 & $3+$ & $\mathrm{P}$ & WT & Neg \\
\hline 24 & $3+$ & $P$ & WT & $\mathrm{Neg}$ \\
\hline 25 & $3+$ & A & WT & Pos \\
\hline 26 & $2+$ & P* & WT & Pos \\
\hline 27 & $2+$ & $\mathrm{P}$ & WT & Neg \\
\hline \multirow[t]{4}{*}{ Total } & $5 / 27(19 \%)$ & $8 / 27(30 \%) A$ & 17/27 (63\%) WT & $16 / 27=59 \%$ Pos \\
\hline & score I+ & & & \\
\hline & $\begin{array}{c}9 / 27(33 \%) \\
\text { score } 2+\end{array}$ & 16/27 (59\%) P & $\begin{array}{c}10 / 27(37 \%) \\
\text { Mutated }\end{array}$ & $1 \mathrm{l} / 27=42 \% \mathrm{Neg}$ \\
\hline & $\begin{array}{c}13 / 27(48 \%) \\
\text { score } 3+\end{array}$ & $3 / 27(11 \%) E$ & & \\
\hline
\end{tabular}

Abbreviations: A, EGFR gene amplification; P, chromosome 7 polysomy; P*, polysomy with rare cells showing EGFR amplification; E, eusomy; WT, wild type; Pos, positive; Neg, negative. 

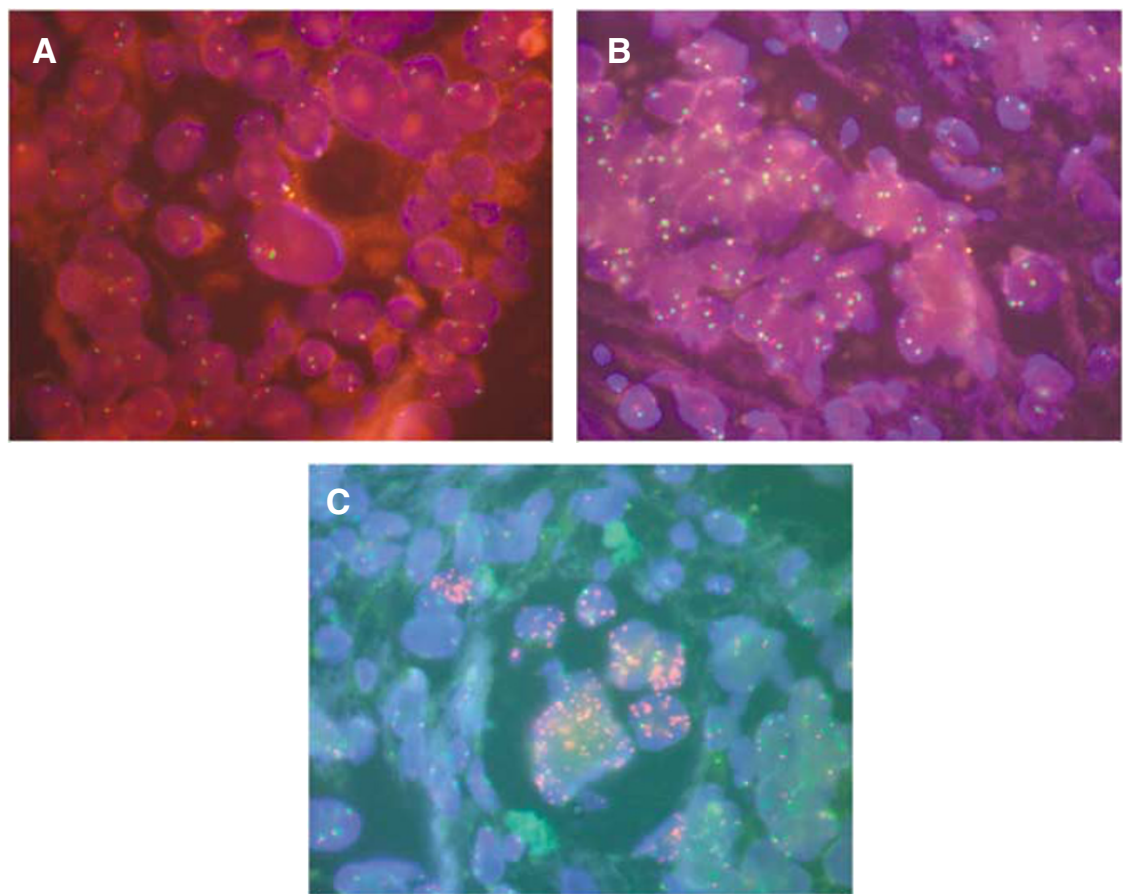

Figure I Epidermal growth factor receptor gene status evaluated by FISH in metastatic colorectal cancers. (A) Patient showing eusomy of chromosome 7. (B) Patient with marked polysomy on chromosome 7. (C) Patient with EGFR gene amplification in at least $10 \%$ of tumoral cells.

\section{K-Ras status}

Seventeen patients did not show $K$-Ras mutations. Point mutations were found in $37 \%$ of cases, in seven patients on codon 12 and in three patients on codon 13 (Table 2). Mutations on codon 12 predominantly involved the second base, with prevalence of the GaT mutation ( $G G T \rightarrow G a T$, Gly $\rightarrow$ Asp, G12D), which was observed in four cases. In one case, the mutation on codon 12 involved the first base $(G G T \rightarrow t G T$, Gly $\rightarrow$ Cys, G12C). No GtT alteration on codon 12 was found, which represents one of the most frequent mutations observed in sporadic CRC. The mutations found on codon 13 corresponded to the transition $G \rightarrow A$ to the second base of the codon $(G G C \rightarrow G a C$, Gly $\rightarrow$ Asp, G13D).

\section{PTEN: IHC}

Normal PTEN expression was documented in 16 (59\%) patients, while loss of PTEN protein expression was found in 11 patients (Figure 2).

\section{Molecular markers and response to cetuximab}

Eusomic patients did not respond to cetuximab-based therapy. An objective response was observed in four out $16(25 \%)$ patients with polysomy, while six out eight (75\%) patients with EGFR amplification were considered as responders (Table 3). The correlation of the EGFR gene status and response reached statistical significance $(P<0.05)$.

Only one out $10(10 \%)$ patients with mutated $K$-Ras experienced a response to cetuximab-based therapy, while nine out of $17(53 \%)$ patients with wild-type sequence had a benefit from therapy. The correlation of the $K$-Ras status and response reached statistical significance $(P<0.05)$ (Table 3$)$. The kind of mutation observed did not influence the response.

As regards to PTEN, 10 of $16(62.5 \%)$ patients with intact protein expression had an objective response to cetuximab-based therapy (Table 3 ). In contrast, none of the 11 patients with loss of
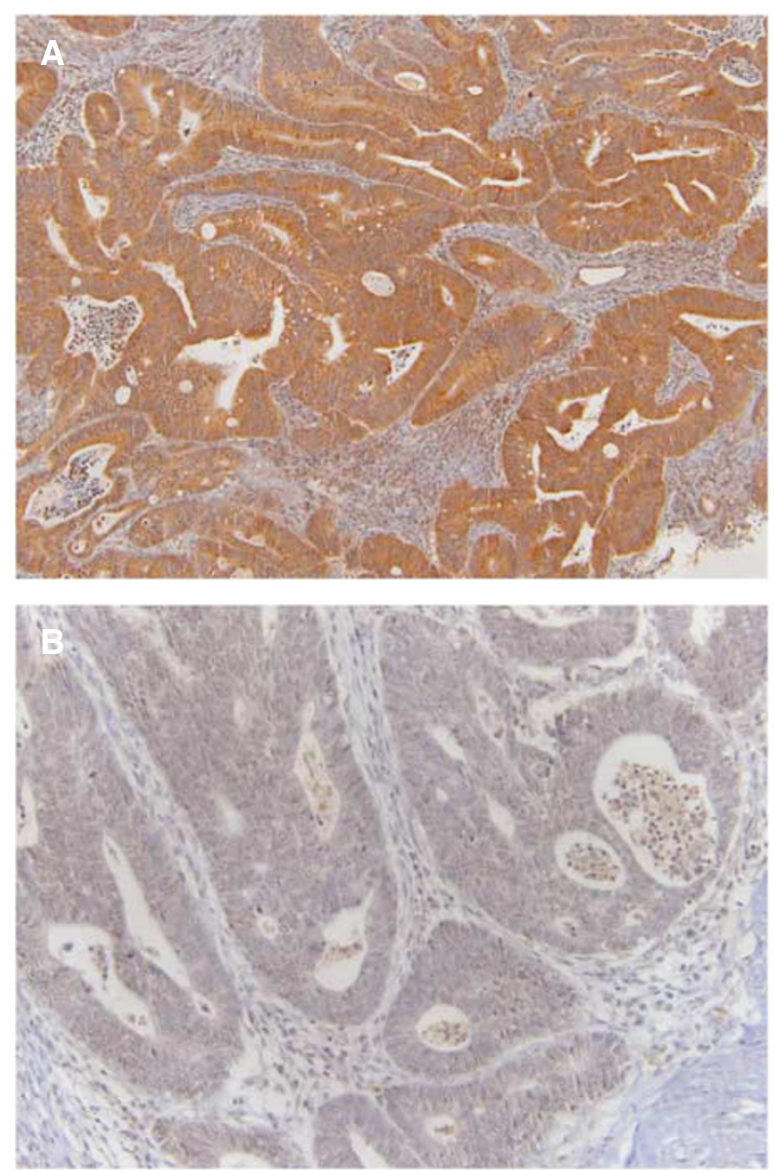

Figure $\mathbf{2}$ PTEN protein expression by immunohistochemistry in metastatic colorectal cancers. (A) Patient showing normal PTEN expression (B) Patient with absent PTEN expression. 
Table 3 EGFR and K-Ras gene status, PTEN protein expression: correlation with clinical response to cetuximab

\begin{tabular}{|c|c|c|c|c|c|c|c|}
\hline & \multicolumn{3}{|c|}{ EGFR (FISH) } & \multicolumn{2}{|c|}{ K-Ras } & \multicolumn{2}{|c|}{ PTEN } \\
\hline & $\mathbf{E}$ & $\mathbf{P}$ & $\mathbf{A}$ & WT & Mut & Pos & Neg \\
\hline Clinical response to PR & 0 & 4 & 6 & 9 & I & 10 & 0 \\
\hline Cetuximab NR & 3 & 12 & 2 & 8 & 9 & 6 & | | \\
\hline Fisher exact test & \multicolumn{3}{|c|}{$P<0.05$} & \multicolumn{2}{|c|}{$P<0.05$} & \multicolumn{2}{|c|}{$P<0.001$} \\
\hline
\end{tabular}

Abbreviations: PR, partial response; NR, nonresponder; E, eusomy; P, chromosome 7 polysomy; A, EGFR gene amplification; WT, wild type; Mut, mutated; Pos, positive; Neg, negative.

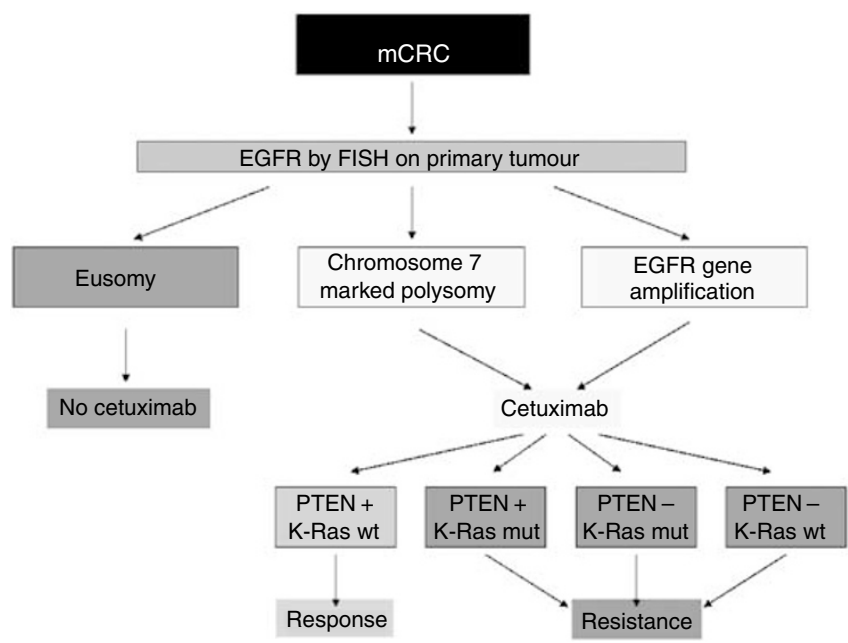

Figure 3 Algorithm in predicting response to cetuximab according to the EGFR and K-Ras status, and PTEN protein expression.

PTEN protein expression had an objective benefit from the MoAb $(P<0.001)$.

\section{DISCUSSION}

The Food and Drug Administration (FDA) approved cetuximab in 2004 for treatment of mCRC in combination with irinotecan, as well as in monotherapy in patients intolerant to irinotecan. However, only a minority of patients respond to cetuximab-based therapy, and there are currently no molecular markers able to identify patients who will benefit from this therapeutic approach. A better understanding of molecular mechanisms that may predict resistance or response to cetuximab is therefore urgently needed.

Similarly to previous reports (Cunningham et al, 2004; Saltz et al, 2004), we observed no correlation between the intensity of EGFR expression as detected by IHC and response to cetuximabbased therapy. In the present cohort, eusomic patients who did not respond to cetuximab were actually classified either score $1+$ $(66 \%)$ or score $3+(33 \%)$. These results are in agreement with those from two small trials, showing that EGFR evaluation using IHC is misleading in predicting response to the MoAb. Moreover, in a retrospective series of 16 chemo-refractory patients not expressing EGFR, cetuximab was shown to produce an RR of $25 \%$ (Chung et al, 2005). In addition, two PR were seen in nine patients with EGFR-negative tumours enrolled in a phase II study of single agent cetuximab (Lenz et al, 2005). It has been shown that the choice of fixative and storage time of tumour tissue, (Atkins et al, 2004) the choice of primary antibody and scoring system (Kersting et al, 2006), and the lack of standardised criteria for evaluation (Langner et al, 2004) all represent potential pitfalls and have a substantial impact on determination of EGFR immunoreactivity. It is therefore highly questionable whether $\mathrm{mCRC}$ patients should be selected for cetuximab-based therapy only on EGFR reactivity by IHC.

Our results indicate that both high polysomy on chromosome 7 and EGFR gene amplification appear to be a pre-requisite for response to cetuximab (observed in 25 and $75 \%$ of cases, respectively). Supporting this hypothesis, three eusomic patients had no benefit from the MoAb. Our findings are consistent with those reported (Moroni et al, 2005; Lievre et al, 2005). Of note, in one of these, patients with trisomy were defined as polysomic and benefited from the drug in $89 \%$ of cases (Moroni et al, 2005). In our series, however, 12 cases with high polysomy on chromosome 7 and two cases with EGFR gene amplification did not benefit from cetuximab. Consequently, the evaluation of the EGFR gene status appears to be insufficient to predict response to the MoAb.

In the present cohort, the majority $(90 \%)$ of patients with mutated K-Ras did not benefit from cetuximab. Similar results have been reported in two additional trials, whereas in another study a not significant trend was observed. If we pool our data with those of these three studies (Moroni et al, 2005; Lievre et al, 2006; Di Fiore et al, 2007), the difference between K-Ras mutated and $K$-Ras wild-type sequence patients as regards to cetuximab treatment is highly significant, indicating that the assessment of $K$-Ras mutations in mCRC plays a fundamental role in predicting cetuximab efficacy. As regards to the type of $K$-Ras mutation, the mostly observed alterations occurred on codon 12 (70\%), against $30 \%$ on codon 13 . These findings are consistent with previous reports (Frattini et al, 2004). Interestingly, besides the expected occurrence of $\mathrm{GaT}$ mutation, no alterations of $\mathrm{GtT}$ (the other most frequently observed K-Ras mutation in sporadic CRC) (Frattini et al, 2004) were found on codon 12 . The present data reinforce, therefore, the knowledge that the GtT mutation typically correlates with an indolent clinical course, and seldom occurs in mCRC (Sarli et al, 2004).

Other factors besides the EGFR gene status and $K$-Ras mutations are likely to be involved in mechanisms of resistance to cetuximab. The EGFR signal activation leads not only to downstream effects on Ras-MAP kinase pathway, but also regulates the PTEN-PI3KAkt cascade. The loss of expression of PTEN protein has been observed in $30 \%$ of sporadic CRC (Thomas and Grandis, 2004). No data on PTEN protein expression and correlation with response to cetuximab in mCRC have been reported yet. We demonstrate that loss of PTEN protein expression may be a useful marker in predicting response to cetuximab. In fact, none of the 11 patients with loss of PTEN expression did benefit from the treatment with MoAb, while a response was observed in 10 out of 16 patients with intact PTEN expression. The six patients with intact PTEN expression who did not benefit from cetuximab had $K$-Ras mutation in four cases, eusomy in one case and both in one case: all these factors have been shown to predict resistance to cetuximab.

The effect of PTEN expression on cetuximab response is similar to the one observed in trastuzumab-treated breast cancer patients (Pandolfi, 2004), supporting the concept that PTEN expression plays a fundamental role in predicting the response to drugs against HER family members.

The population of the present study is comparable with those of previous related studies in terms of included patients, and it is homogeneous since it encompasses unselected patients native from an isolated geographic area, all evaluated and treated in one institution. None of the patients were found to exhibit MSI, which suggests that tumour development in our patients followed the same pathway (Fearon and Vogelstein, 1990). Actually, the rate of PR $(37 \%)$ is surprisingly high when compared with published data of pivotal trials including cetuximab (Cunningham et al, 2004). On the other hand, our cohort is characterised by high frequency of polysomy and EGFR gene amplification. We can therefore 
speculate that environmental and lifestyle factors might lead both to frequent cell division deregulation (as deductible by the observed high rate of polysomy) and to EGFR gene amplification. Although the clinical course might be more aggressive, this particular constellation makes perhaps a targeted approach more effective than expected.

The possibility that the present findings are related to the response to the previous chemotherapy regimen rather than cetuximab sensitivity or resistance may raise questions on the validity of our as well as previous results. This hypothesis, however, is unlikely since all patients included in this study were refractory to previous chemotherapeutic treatment, and drugs, such as fluoropirimidines, oxaliplatin and irinotecan, act against thymidylate synthase and topoisomerase I and not against the EGFR signalling pathway.

Overall, our findings allow to propose an algorithm in order to possibly select patient for cetuximab therapy (Figure 3 ). Those presenting with eusomy on chromosome 7 are more likely to be refractory to the MoAb, while patients with high polysomy or EGFR gene amplification should be considered for cetuximab therapy. A benefit from the MoAb may be expected in patients presenting with wild-type $K$-Ras and intact PTEN expression. Only one patient escaped to this algorithm, in that he responded to cetuximab in presence of $K$-Ras mutation. A possible explanation could be that in our series all molecular analysis have been performed on primary CRC, and the gene profile on primary tumour and metastasis might differ, as previously reported (Scartozzi et al, 2004).

In conclusion, our results indicate that different downstream proteins of the EGFR cascade have a deep effect on response to cetuximab. In particular, this is the first report on the predictive role of the expression of PTEN protein in mCRC. These data, which need to be validated in large prospective clinical trials, might represent a valid platform for oncologists in selecting patients for cetuximab-based therapy, with evident clinical and economical consequences.

\section{ACKNOWLEDGEMENTS}

This work was funded by Oncosuisse, grant OCS-01921-08-2006.

\section{REFERENCES}

Atkins D, Reiffen KA, Tegtmeier CL, Winther H, Bonato MS, Storkel S (2004) Immunohistochemical detection of EGFR in paraffin-embedded tumor tissues: variation in staining intensity due to choice of fixative and storage time of tissue sections. J Histochem Cytochem 52: 890-893

Baselga J (2001) The EGFR as a target for anticancer therapy: focus on cetuximab. Eur J Cancer 37(Suppl 4): S16-S22

Borner M, Mingrone W, Koeberle D, Von Moos R, Rauch D, Saletti P, Herrmann R, Dietrich D, Lanz D, Roth A (2006) The impact of cetuximab on the capecitabine plus oxaliplatin (XELOX) combination in first-line treatment of metastatic colorectal cancer (MCC): a randomised phase II trial of the Swiss Group for Clinical Cancer Research (SAKK). J Clin Oncol 24(18S): 3551

Chung KY, Shia J, Kemeny NE, Shah M, Schwartz GK, Tse A, Hamilton A, Pan D, Schrag D, Schwartz L, Klimstra DS, Fridman D, Kelsen DP, Saltz LB (2005) Cetuximab shows activity in colorectal cancer patients with tumors that do not express the epidermal growth factor receptor by immunohistochemistry. J Clin Oncol 23: $1803-1810$

Cunningham D, Humblet Y, Siena S, Khayat D, Bleiberg H, Santoro A, Bets D, Mueser M, Harstrick A, Verslype C, Chau I, Van Cutsem E (2004) Cetuximab monotherapy and cetuximab plus irinotecan in irinotecan-refractory metastatic colorectal cancer. $N$ Engl J Med 351: $337-345$

Di Fiore F, Bianchard F, Charbonnier F, Le Pessot F, Lamy A, Galais MP, Bastit L, Killian A, Sesboüé R, Tuech JJ, Queuniet AM, Paillot B, Sabourin JC, Michot F, Michel P, Frebourg T (2007) Clinical relevance of KRas mutation detection in metastatic colorectal cancer treated by cetuximab plus chemotherapy. Br J Cancer 96: 1166-1169

Fearon ER, Vogelstein B (1990) A genetic model for colorectal tumorigenesis. Cell 61: $759-767$

Folprecht G, Lutz MP, Schoffski P, Seufferlein T, Nolting A, Pollert P, Kohne CH (2006) Cetuximab and irinotecan/5-fluorouracil/folinic acid is a safe combination for the first-line treatment of patients with epidermal growth factor receptor expressing metastatic colorectal cancer. Ann Oncol 17: $450-456$

Frattini M, Balestra D, Suardi S, Oggionni M, Alberici P, Radice P, Costa A, Daidone MG, Leo E, Pilotti S, Bertario L, Pierotti MA (2004) Different genetic features associated with colon and rectal carcinogenesis. Clin Cancer Res 10: 4015-4021

Frattini M, Signoroni S, Pilotti S, Bertario L, Benvenuti S, Zanon C, Bardelli A, Pierotti MA (2005) Phosphatase protein homologue to tensin expression and phosphatidylinositol-3 phosphate kinase mutations in colorectal cancer. Cancer Res 65: 11227

Jennis A, Polikoff J, Mitchell E, Badarinath S, Graham C, Chen T, Gustafson T, Langer C (2005) Erbitux (Cetuximab) plus FOLFOX for colorectal cancer (EXPLORE): preliminary efficacy analysis of a randomised phase III trial. J Clin Oncol 23(16S): 3574
Kersting C, Packeisen J, Leidinger B, Brandt B, von Wasielewski R, Winkelmann W, van Diest PJ, Gosheger G, Buerger H (2006) Pitfalls in immunohistochemical assessment of EGFR expression in soft tissue sarcomas. J Clin Pathol 59: 585-590

Langner C, Ratschek M, Rehak P, Schips L, Zigeuner R (2004) Are heterogeneous results of EGFR immunoreactivity in renal cell carcinoma related to non-standardised criteria for staining evaluation? J Clin Pathol 57: $773-775$

Lenz HJ, Mayer RJ, Gold PJ, Mirtsching B, Stella PJ, Cohn AL, Pippas AW, Azarnia N, Needle MN, Van Cutsem E (2005) Activity of cetuximab in patients with colorectal cancer refractory both irinotecan and oxaliplatin. $J$ Clin Oncol 22(14S): 3510

Lievre A, Bachet JB, Le Corre D, Boige V, Landi B, Emile JF, Cote JF, Tomasic G, Penna C, Ducreux M, Rougier P, Penault-Llorca F, Laurent-Puig P (2005) KRAS mutation status is predictive of response of cetuximab therapy in colorectal cancer. Cancer Res 66: $3992-3995$

Mayer A, Takimoto M, Fritz E, Schellander G, Kofler K, Ludwig H (1993) The prognostic significance of proliferating cell nuclear antigen, epidermal growth factor receptor, and mdr gene expression in colorectal cancer. Cancer 71: 2454-2460

Moroni M, Veronese S, Benvenuti S, Marrapese G, Sartore-Bianchi A, Di Nicolantonio F, Gambacorta M, Siena S, Bardelli A (2005) Gene copy number for epidermal growth factor receptor (EGFR) and clinical response to antiEGFR treatment in colorectal cancer: a cohort study. Lancet Oncol 6: 279-286

Pandolfi PP (2004) Breast cancer - loss of PTEN predicts resistance to treatment. $N$ Engl J Med 351: 2337-2338

Rosenberg AH, Loehrer PJ, Needle MN, Waksal H, Hollywood E, Ramos L, Saltz LB (2002) Erbitux (IMC-C225) plus weekly irinotecan (CPT-11), fluorouracil (5FU) and leucovorin (LV) in colorectal cancer (CRC) that express the epidermal growth factor receptor (EGFr). Proc Am Soc Clin Oncol 21: 536

Saal LH, Holm K, Maurer M, Memeo L, Su T, Wang X, Yu JS, Malmstrom PO, Mansukhani M, Enoksson J, Hibshoosh H, Borg A, Parsons R (2005) PIK3CA mutations correlate with hormone receptors, node metastasis, and ERBB2, and are mutually exclusive with PTEN loss in human breast carcinoma. Cancer Res 65: 2554-2559

Saltz L, Rubin M, Hochster H, Tchekmeydian NS, Waksal H, Needle M, LoBuglio A (2001) Cetuximab (IMC-C225) plus irinotecan (CPT-11) is active in CPT-11-refractory colorectal cancer (CRC) that expresses epidermal growth factor receptor. Proc Am Soc Clin Oncol 20: 7

Saltz LB, Meropol NJ, Loehrer Sr PJ, Needle MN, Kopit J, Mayer RJ (2004) Phase II trial of cetuximab in patients with refractory colorectal cancer that express the epidermal growth factor receptor. J Clin Oncol 22: $1201-1208$ 
Sarli L, Bottarelli L, Bader G, Iusco D, Pizzi S, Costi R, D’Adda T, Bertolani M, Roncoroni L, Bordi C (2004) Association between recurrence of sporadic colorectal cancer, high level of microsatellite instability, and loss of heterozygosity at chromosome 18q. Dis Colon Rectum 47: 1467-1482

Scartozzi M, Bearzi I, Berardi R, Mandolesi A, Fabris G, Cascinu S (2004) Epidermal growth factor receptor (EGFR) status in primary colorectal tumors does not correlate with EGFR expression in related metastatic sites: implications for treatment with EGFR-targeted monoclonal antibodies. J Clin Oncol 22: $4772-4778$

Tabernero JM, Van Cutsem E, Sastre J, Cervantes A, Van Laethem JL, Humblet Y, Soulié P, Corretgé S, Mueser M, De Gramont A (2004) An international phase II study of cetuximab in combination with oxaliplatin/5-fluorouracil (5-FU)/folinic acid (FA) (FOLFOX-4) in the first-line treatment of patients with metastatic colorectal cancer (CRC) expressing epidermal growth factor receptor (EGFR). Preliminary results. J Clin Oncol 22(14S): 3512

Therasse P, Arbuck SG, Eisenhauer EA, Wanders J, Kaplan RS, Rubinstein L, Verweij J, Van Glabbeke M, van Oosterom AT, Christian MC, Gwyther SG (2000) New guidelines to evaluate the response to treatment in solid tumors. J Natl Cancer Inst 92: 205-216
Thomas SM, Grandis JR (2004) Pharmacokinetic and pharmacodynamic properties of EGFR inhibitors under clinical investigation. Cancer Treat Rev 30: $255-268$

Van Laethem JL, Raoul JL, Mitry E, Brezault C, Husseini F, Cals L, Vedovato JC, Mueser MM, Rougier P (2003) Cetuximab (C225) in combination with bi-weekly irinotecan (CPT-11), infusional 5-fluorouracil (5FU) and folinic acid (FA) in patients (pts) with metastatic colorectal cancer (CRC) expressing the epidermal growth factor receptor (EGFR). Preliminary safety and efficacy results. Proc Am Soc Clin Oncol 22: 1058

Venook A, Niedzwiecki D, Hollis D, Sutherland S, Goldberg R, Alberts S, Benson A, Wade J, Schilski R, Mayer R (2006) Phase III study of irinotecan/5FU/LV (FOLFIRI) or oxaliplatin/5FU/LV (FOLFOX) +/Cetuximab for patients (pts) with untreated metastatic adenocarcinoma of the colon or rectum (MCRC): CALGB 80203 preliminary results. J Clin Oncol 24(18S): 3509

Wilke H, Glynne-Jones R, Thaler J, Adenis A, Preusser P, Aranda Aguilar E, Aapro M, Van Den Berg N, Eggleton S, Siena S (2006) MABEL-A large multinational study of cetuximab plus irinotecan in irinotecan resistant metastatic colorectal cancer. J Clin Oncol 24(18S): 3549 